\title{
Prevalence of methicillin-resistant
} among patients attending regional hospitals in Dar es Salaam, Tanzania

Agricola Joachim ${ }^{1 *} \mathbb{0}$, Sabrina J. Moyo ${ }^{1,2}$, Lillian Nkinda ${ }^{1}$, Mtebe Majigo ${ }^{1}$, Elia Mmbaga ${ }^{3}$, Naboth Mbembati ${ }^{4}$, Said Aboud ${ }^{1}$ and Eligius F. Lyamuya ${ }^{1}$

\begin{abstract}
Background: Methicillin-resistant Staphylococcus aureus (MRSA) is a major pathogen responsible for hospital and community acquired infection. Colonization with MRSA is associated with a high risk of developing infection. This study aimed to determine the rate of MRSA carriage on admission and the associated risk factors among patients attending regional hospitals, in Dar es Salaam, Tanzania.

Results: A total of 258 patients were included in this study. Nasal swabs were collected on admission to the hospital and after $48 \mathrm{~h}$ of hospital stay for detection of MRSA. Of 258 patients enrolled, 89 (34.5\%) were colonized with S. aureus and out them 22 (24.7\%) were carriers of MRSA, giving an overall MRSA nasal carriage rate of 8.5\% (22/258). One patient acquired MRSA while admitted in the hospital. Most of the S. aureus isolates 85 (95.5\%) were resistant to penicillin. Resistance to gentamycin, ciprofloxacin, kanamycin, linezolid and mupirocin were 14.6, 11.2, 11.2, 3.4 and $1.1 \%$, respectively. The prevalence of inducible clindamycin resistance, constitutive clindamycin resistance, MS phenotype (resistance to erythromycin alone), and multidrug resistance was 21.3, 3.4, 12.4, and 16.9\%, respectively. We observed a statistically significant association between MRSA and multiple drugs resistance among $S$. aureus isolates $(p=0.001)$. Of the risk factors investigated none were statistically significant associated with MRSA.

Conclusion: There is a high prevalence of MRSA among patients on admission at the two municipal hospitals in Dar es Salaam. The high prevalence of MRSA and the increased rates of resistance to commonly used antimicrobials among MRSA isolates call for attention to the importance of including the screening of MRSA in our hospitals setting in order to prevent further spread of MRSA strains to other patients and to the communities. Control and prevention strategies should be emphasized including decolonization.
\end{abstract}

Keywords: MRSA nasal carriage, Infection, Antibiotic resistance

\section{Background}

Methicillin-resistant Staphylococcus aureus (MRSA) is an important cause of hospital-acquired infection leading to a high morbidity and mortality among patients worldwide. Recent studies have also reported increasing

\footnotetext{
*Correspondence: agricolaj@muhas.ac.tz; agricolaj@yahoo.com 1 Department of Microbiology and Immunology, Muhimbili University of Health and Allied Sciences, Dar Es Salaam, Tanzania

Full list of author information is available at the end of the article
}

rates of MRSA infections in the community settings, which are referred to as Community acquired MRSA [1, 2]. MRSA remains a major pathogen in nosocomial infections in developing countries [3]. Carriage of antimicrobial-resistant strain like MRSA puts an individual at high risk of developing infection [4]. The rate of developing infection following MRSA colonization is reported to be approximately $30 \%[4,5]$. Of concern is the high mortality associated with MRSA infections. Infection due to $S$. aureus ranges from mild to moderate skin and soft tissue 
infections to invasive life-threatening systemic infections [6].

Carriage rates or infections with MRSA vary by geographical location, type of health care facility, and the specific population being studied. Studies have reported prevalence of MRSA carriage on admission ranging from 2.6 to $8 \%$ with higher prevalence reported among elderly patients [7-11]. Reports have shown that approximately $80-95 \%$ of MRSA carriages are asymptomatic [12]. However, harboring of MRSA strains during the time of hospital admission may have negative consequences not only on patients' management but also affect the implementation of infection control measures in the hospital especially where resources are limited [3]. One of the consequences of admitted patients who are carrying MRSA is the increase in the risk of transmitting the pathogen to other patients and health workers [13, 14]. Populations at risk of acquiring MRSA infection include people with underlying chronic infections [15-17]. Such conditions may result in severe complications and fatal consequences, especially if multiple antibiotic resistant strains are involved. Other reported risk factors for MRSA acquisition include prolonged hospitalization, visiting an outpatient clinic, patients with a skin or softtissue infection, working in health care facilities as well as history of antibiotic use [17-20]. However, the risk factors for MRSA colonization at the time of hospital admission among patients are not well known. Identifying MRSA colonization at admission could target a highrisk population that may benefit from interventions to decrease the risk for developing MRSA infection.

Studies have shown that strategies to screen for colonized patients at admission and decolonize them may lead to the reduction of the transmission rate of MRSA $[21,22]$. Elimination of MRSA carriage through the application of decolonization agents, such as nasal mupirocin and chlorhexidine soap has been reported elsewhere [14].

Development of resistance to antimicrobial agents among staphylococci is an increasing problem worldwide [23]. The increasing rate of MRSA multiple-drug resistant strains, which limits the therapeutic options available for the management of MRSA related infections, has become a serious concern worldwide. Several studies have reported the use of macrolide-lincosamidestreptogramin $\mathrm{B}\left(\mathrm{MLS}_{\mathrm{B}}\right)$ in the treatment of staphylococcal infections, where clindamycin is used as alternative treatment. However risks of treatment failure due $\mathrm{MLS}_{\mathrm{B}}$ inducible resistance are reported to frequently increase [24-26].

Previous studies conducted in Tanzania at Muhimbili national hospital $(\mathrm{MNH})$ and Bugando medical center have documented an increasing prevalence of hospitalacquired MRSA; 0.4\% [27], 8\% [28], 16.3\% [29] and 23\%
[30]. These studies used clinical specimens from hospitalized patients who presented with symptoms and/or signs of infection. In Tanzania, no study has been conducted on MRSA screening among patients at the time of admission to hospitals. The current study was undertaken to investigate the rate of MRSA carriage on admission and the associated risk factors among patients attending the Amana and Mwananyamala regional hospitals in Dar es Salaam, Tanzania.

\section{Methods}

\section{Study design and sampling procedures}

This was a hospital based cross-sectional study conducted at two regional hospitals, Mwananyamala and Amana in Dar es Salaam, Tanzania. Using Kish-Leslie formula and a reported prevalence of MRSA of $23 \%$ at $\mathrm{MNH}$, Dar es Salaam Tanzania by Moyo et al. [30], a minimum sample size of 283 was targeted. However, were able to enroll 258 patients. All eligible patients admitted at emergency department or medical ward between March and August 2015 were recruited in the study after obtained an informed consent. Children below 5 years of age and patients who were using antibiotic at the time of recruitment or within 2 weeks were excluded. Structured questionnaire was used to collect social demographic information including age, sex, level of education and residence. Risk factors associated with MRSA including current and previous medical history and use of antibiotic in the past 3 months were also collected. Furthermore, patients who stayed in the hospital for $48 \mathrm{~h}$ or more following admission were requested to provide a second set of nasal specimen. These were the same patients whom we collected nasal samples on admission and were more likely to have serious illness compared to other patients. A total of 20 patients were available for second sample collection.

\section{Sample collection and transportation}

Well-trained health personnel collected nasal specimens from both anterior nares of each patient using a sterile cotton wool swab on admission. Second set of nasal swab was collected $48-72 \mathrm{~h}$ after admission. Nasal swabs were placed in Stuart transport media and transported to the microbiology and immunology laboratory at Muhimbili University of Health and Allied Sciences (MUHAS) and processed within $24 \mathrm{~h}$ of collection.

\section{Laboratory procedures}

Nasal swabs were inoculated into mannitol salt agar plates (OXOID, Basingstoke, United Kingdom) for S. aureus isolation. The plates were incubated at $37{ }^{\circ} \mathrm{C}$ and examined for growth after 24-48 h. Isolates were identified as $S$. aureus based on colonial morphology, gram staining, catalase test, coagulase test and DNase test positive. The 
antimicrobial susceptibility testing was carried out using Kirby-Bauer's disc diffusion method according to clinical and laboratory standards institute (CLSI) 2015 guidelines [31]. The following standard antibiotic disks (OXOID UK) were used; penicillin G (10 U), kanamycin $(30 \mu \mathrm{g})$, gentamicin $(10 \mu \mathrm{g})$, erythromycin $(15 \mu \mathrm{g})$, clindamycin $(2 \mu \mathrm{g})$, ciprofloxacin $(5 \mu \mathrm{g})$, linezolid $(30 \mu \mathrm{g})$ and mupirocin $(5 \mu \mathrm{g})$. A standard inoculum was prepared by direct colony suspension in saline and compared with $0.5 \mathrm{McFar}-$ land standard turbidity and inoculated on Muller Hinton agar plate (OXOID UK). Plates were incubated at $35^{\circ} \mathrm{C}$ for 18-24 h. Results were interpreted according to the CLSI guidelines [31]. MRSA detection was done using cefoxitin discs (OXOID UK) according to CLSI 2015 guidelines. All isolates resistant to cefoxitin were considered as MRSA. An inhibition zone of $21 \mathrm{~mm}$ or less around cefoxitin disc indicated MRSA [31]. S. aureus ATCC 25923 was used for quality control.

In addition clindamycin inducible resistance was also tested by D test as per CLSI guidelines [31]. Briefly, erythromycin $(15 \mu \mathrm{g})$ disk was placed at a distance of $15-26 \mathrm{~mm}$ (edge to edge) from clindamycin $(2 \mu \mathrm{g})$ disk on a Mueller-Hinton agar plate. After overnight incubation, plates were examined for the formation of flattened zone of inhibition adjacent to the erythromycin disk. Formation of D-shape with erythromycin indicated a positive clindamycin inducible resistant $\left(\mathrm{iMLS}_{\mathrm{B}}\right)$. Resistance to both clindamycin and erythromycin was recorded as constitutive resistance $\left(\mathrm{cMLS}_{\mathrm{B}}\right)$ and MS phenotype if the isolate was resistant to erythromycin only [31].

\section{Data analysis}

Data obtained were analysed using statistical program for social sciences (SPSS) version 17.0. Chi square test or Fisher's exact test was used where applicable to compare the proportions of categorical independent and dependent variables. Univariate and multivariate analysis were performed to determine the risk factors associated with nasal $S$. aureus and MRSA colonization. A $p$ value of $<0.05$ was considered as statistically significant.

\section{Results}

A total of 258 patients were enrolled during the study period. Of these, $150(58.1 \%)$ were females. The mean age was 34 years, ranging from 10 to 80 years. Half of the patients 129 (50\%) were from Kinondoni, 97 (38\%) from Ilala and 32 (12\%) from Temeke districts. Majority of the patients $133(51.6 \%)$ had informal or attained primary education. Of 258 patients, 20 (7.8\%) had history of previous hospitalization while 60 (23\%) had attended outpatient clinic prior to the current admission. Thirty-seven (14.3\%) patients had received antibiotics within the past 3 months.

\section{Nasal carriage of S. aureus, MRSA, and antibiotic susceptibility patterns}

A total of 89/258 (34.5\%) S. aureus were isolated from the samples collected on admission to the hospital. Of the 89 isolates, $22(24.7 \%)$ were MRSA while $67(75.3 \%)$ were methicillin susceptible $S$. aureus (MSSA) making the overall prevalence of MRSA among all patients to be 22/258 (8.5\%). Only 20 patients were available for second samples collection due to the fact that most of the patients were discharged from the hospital before $48 \mathrm{~h}$ of admission. Of the 20 samples collected, four had S. aureus isolated, and two out of these had MRSA carriage. One patient had MRSA on admission while the second one was MRSA negative on admission. Table 1 shows the characteristics of the patients at admission to the hospital, according to their MRSA status (positive or negative). Of the total number of patients colonized with MRSA, more than half 12 (54.5\%) were male, half $11(50 \%)$ were aged $18-30$ years and $13(59.1 \%)$ had informal or primary education level. Most of patients who tested MRSA positive 21 (95.5\%) had no history of previous hospital admission and 18

Table 1 Characteristics of study participants with and without MRSA

\begin{tabular}{|c|c|c|}
\hline Characteristic & $\begin{array}{l}\text { MRSA positive } \\
\mathrm{N}=22 \\
\mathrm{n}(\%)\end{array}$ & $\begin{array}{l}\text { MRSA negative } \\
\mathrm{N}=236 \\
\mathrm{n}(\%)\end{array}$ \\
\hline \multicolumn{3}{|l|}{ Age group in years } \\
\hline $7-17$ & $3(13.6)$ & $21(8.9)$ \\
\hline $18-30$ & $11(50)$ & $91(38.6)$ \\
\hline $31-60$ & $7(31.8)$ & $102(43.2)$ \\
\hline$>60$ & $1(4.5)$ & $22(9.3)$ \\
\hline \multicolumn{3}{|l|}{ Sex } \\
\hline Male & $12(54.5)$ & $96(40.7)$ \\
\hline Female & $10(45.5)$ & $140(59.3)$ \\
\hline \multicolumn{3}{|l|}{ Education attained } \\
\hline Primary education and below & $13(59.1)$ & $120(50.8)$ \\
\hline Secondary education and above & $9(40.9)$ & $116(49.2)$ \\
\hline \multicolumn{3}{|l|}{ History of antibiotic use } \\
\hline Yes & $4(18.2)$ & $33(14.0)$ \\
\hline No & $18(81.8)$ & $203(86.0)$ \\
\hline \multicolumn{3}{|l|}{ History of hospitalisation } \\
\hline Yes & $1(4.5)$ & $19(8.1)$ \\
\hline No & $21(95.5)$ & $217(91.9)$ \\
\hline \multicolumn{3}{|l|}{ History of attending OPC } \\
\hline Yes & $4(18.2)$ & $56(23.7)$ \\
\hline No & $18(81.8)$ & $180(76.3)$ \\
\hline \multicolumn{3}{|l|}{ Type of illness on admission } \\
\hline Chronic illness & $5(22.7)$ & $39(16.5)$ \\
\hline Acute illness & $17(77.3)$ & $197(83.5)$ \\
\hline
\end{tabular}

OPC outpatient clinic 
(81.8\%) had neither history of attending outpatient clinic nor use of antibiotic in the past 3 months. A higher frequency of MRSA was detected among patients diagnosed with acute illness 17 (77.3\%) on admission compared to patients with chronic illness 5 (22.7\%) Table 1.

Most of the $S$. aureus isolates 85 (95.5\%) were resistant to penicillin. Resistance to gentamycin, ciprofloxacin, kanamycin and linezolid were 14.6, 11.2, 11.2 and 3.4\%, respectively. Only one (1.1\%) isolate that was MSSA was found to be resistant to mupirocin. Antimicrobial resistance pattern of MRSA and MSSA are summarized in Table 2. We found higher rates of resistance to gentamycin, ciprofloxacin and kanamycin among MRSA isolates compared to MSSA isolates, $(\mathrm{p}=0.00)$.

The prevalence of $\mathrm{iMLS}_{\mathrm{B}}, \mathrm{CMLS}_{\mathrm{B}}$, MS phenotype, and MDR was $21.3,3.4,12.4$, and $16.9 \%$, respectively. There was a statistically significant association between MRSA and multiple drugs resistance (MDR) among $S$. aureus isolates $(\mathrm{p}=0.001)$ (Table 3$)$.

\section{Factors associated with MRSA carriage}

Chronic illness increases the risk of MRSA colonization two times compared to acute illness (odd ratio OR, 1.96 [95\% CI 0.52-7.31]). Male patients are more likely to be MRSA carrier than females with an odds ratio 2.15 [95\% CI

Table 2 Antimicrobial resistance pattern among MRSA and MSSA isolates

\begin{tabular}{llll}
\hline Antimicrobial drug & MRSA & MSSA & p value \\
& $\mathbf{n = 2 2 ( \% )}$ & $\mathbf{n = 6 7 ( \% )}$ & \\
\hline Penicillin & NA & $63(94)$ & \\
Ceftriaxone & NA & 0 & \\
Gentamycin & $10(45.5)$ & $3(4.5)$ & 0.00 \\
Ciprofloxacin & $8(36.4)$ & $2(3)$ & 0.00 \\
Kanamycin & $8(36.4)$ & $2(3)$ & 0.00 \\
Linezolid & $2(9.1)$ & $1(1.5)$ & 0.23 \\
Mupirocin & $0(0)$ & $1(1.5)$ & \\
\hline
\end{tabular}

MRSA methicillin-resistant Staphylococcus aureus, MSSA methicillin-susceptible S. aureus, NA not applicable

Table 3 Prevalence of different antimicrobial resistance type among MRSA and MSSA isolates

\begin{tabular}{lllll}
\hline $\begin{array}{l}\text { Resistance } \\
\text { type }\end{array}$ & $\begin{array}{l}\text { Overall } \\
\mathbf{N}=\mathbf{8 9} \\
\mathbf{n}(\%)\end{array}$ & $\mathbf{n}(\%)$ & $\mathbf{n}(\%)$ & \\
\hline iMLS $_{B}$ & $19(21.3)$ & $7(31.8)$ & $12(17.9)$ & 0.22 \\
CMLS $_{B}$ & $3(3.4)$ & $2(9.1)$ & $1(1.5)$ & 0.14 \\
$\begin{array}{l}\text { MS pheno- } \\
\text { type }\end{array}$ & $11(12.4)$ & $6(27.3)$ & $5(7.5)$ & 0.02 \\
MDR & $19(21.3)$ & $16(72.7)$ & $3(4.5 \%)$ & 0.001 \\
\hline
\end{tabular}

0.81-5.72]. The use of antibiotic within the past 3 months appears to influence the risk of MRSA carriage (OR 1.36 [95\% CI 0.43-4.20]) whereas as history of previous hospitalization or attending outpatient clinic did not influence the rate of MRSA colonization (OR, 0.71 [95\% CI 0.07$6.45]$ and 0.88 [95\% CI 0.25-3.10]), respectively (Table 4).

\section{Discussion}

The present study determined the rate of MRSA carriage on admission among patients attending hospitals in Dar es Salaam. The overall prevalence of MRSA carriage among all patients investigated in this study was $8.5 \%$. These findings are consistent with reports from other studies $[7,8,11]$. We observed a high proportion of MRSA (24.7\%) among patients who were colonized with $S$. aureus. The prevalence reported here is comparable with reports from previous studies conducted in Tanzania [30] but higher than the prevalence reported by Mshana et al. who found a prevalence of $16.2 \%$ [29]. The higher prevalence in our study could be due to differences in the populations studied. While this study was looking for MRSA carriage among admitted patients the other study [29] searched for MRSA from clinical isolates. Differences observed could also be due to different geographical locations of these studies. Our study was conducted in Dar es Salaam, which is considered to be more overcrowded/overpopulated city; this might have increased the risk of transmission.

Previous study has demonstrated that the risk of acquiring MRSA increase with the length of hospital stay [32]. In this study we also aimed to assess the risk of acquiring MRSA for those who were initially free of the organism at the time of admission but acquired the same while in the hospital. Twenty patients were available for second samples collection, $48 \mathrm{~h}$ after admission. One patient who was MRSA negative at the time of admission was MRSA positive after $48 \mathrm{~h}$ of staying in the hospital indicating that the organism was acquired while in the hospital.

The antimicrobial resistance pattern reported in this study shows that MRSA isolates were resistant to most commonly used antibiotics. Resistance to gentamycin, ciprofloxacin and kanamycin were significantly higher among MRSA isolates compared to MSSA. Low resistance towards Linezolid (3.4\%) indicates that this antibiotic might be an option for empirical therapy of MRSA infections at our hospitals. All MRSA isolates were sensitive to mupirocin with only one MSSA isolate (1.1\%) demonstrating resistance. Various rates of mupirocin resistance among MRSA isolates have been described in hospitalized patients ranging from 0 to $65 \%$ [33-37]. Our results indicate that mupirocin is still suitable for decolonization as well as treatment of staphylococcal skin infection in our settings. 
Table 4 Univariate and multivariate association between MRSA carriage and risk factors

\begin{tabular}{|c|c|c|c|c|}
\hline Characteristic & $N=258$ & $\begin{array}{l}\text { MRSA positive } \\
\text { n (\%) }\end{array}$ & $\begin{array}{l}\text { Univariate } \\
\text { p value; OR (95\%) }\end{array}$ & $\begin{array}{l}\text { Multivariate } \\
\text { p value; OR (95\%) }\end{array}$ \\
\hline \multicolumn{5}{|l|}{ Age group in years } \\
\hline $7-17$ & 24 & $3(12.5)$ & $0.29 ; 3.2(0.37-40.5)$ & $0.25 ; 4.1(0.36-47.6)$ \\
\hline $18-30$ & 102 & $11(10.8)$ & $0.178 ; 4.6(0.49-44.5)$ & $0.126 ; 6.1(0.60-63.6)$ \\
\hline $31-60$ & 109 & $7(3.6)$ & $0.99 ; 1.5(-0.57-3.70)$ & $0.88 ; 1.2(0.11-12.7)$ \\
\hline$>60$ & 23 & $1(4.3)$ & 1 & 1 \\
\hline \multicolumn{5}{|l|}{ Sex } \\
\hline Male & 108 & $12(11.1)$ & $0.124 ; 2.15(0.81-5.72)$ & $0.104 ; 2.3(0.84-6.42)$ \\
\hline Female & 150 & $10(6.7)$ & 1 & 1 \\
\hline \multicolumn{5}{|l|}{ Education attained } \\
\hline Primary education and below & 133 & $13(9.8)$ & $0.46 ; 1.39(0.57-3.39)$ & $0.36 ; 1.6(0.57-4.46)$ \\
\hline Secondary education and above & 125 & $9(7.2)$ & 1 & 1 \\
\hline \multicolumn{5}{|l|}{ History of antibiotic use } \\
\hline Yes & 37 & $4(11.0)$ & $0.59 ; 1.36(0.43-4.2)$ & $0.38 ; 1.72(0.5-5.8)$ \\
\hline No & 221 & $18(8.0)$ & 1 & 1 \\
\hline \multicolumn{5}{|l|}{ History of hospitalisation } \\
\hline Yes & 20 & $1(5.0)$ & $0.76 ; 0.715(0.079-6.45)$ & $0.66 ; 0.60(0.63-5.85)$ \\
\hline No & 238 & $21(8.8)$ & 1 & 1 \\
\hline \multicolumn{5}{|l|}{ History of attending OPC } \\
\hline Yes & 60 & $4(6.7)$ & $0.84 ; 0.88(0.25-3.1)$ & $0.92 ; 0.94(0.26-3.33)$ \\
\hline No & 198 & $18(9.1)$ & 1 & 1 \\
\hline \multicolumn{5}{|l|}{ Type of illness on admission } \\
\hline Chronic illness & 44 & $5(11.4)$ & $0.314 ; 1.96(0.52-7.31)$ & $0.41 ; 1.74(0.46-6.57)$ \\
\hline Acute illness & 214 & $17(7.9)$ & 1 & \\
\hline
\end{tabular}

$O P C$ outpatient clinic

The use of macrolide-lincosamide-streptogramin $B$ (MLSB) antibiotics in the treatment of both methicillin susceptible and resistant staphylococcal infections with clindamycin being used as alternative treatment has been reported [24]. In the current study we observed high prevalence of iMLSB in both MRSA and MSSA isolates. Similar observations have been reported by other studies conducted in and outside our settings [23, 26, 29, 30]. The high prevalence of iMLSB is an indication of possible therapeutic failure when using clindamycin in $S$. aureus infection. Notably therapeutic failures caused by macrolide-lincosamide-streptogramin $\mathrm{B}$ inducible resistance are being more commonly reported [26]. A limitation of this study is lack of molecular confirmation and characterization of MRSA strains due to financial constraints making is difficult to determine the circulating MRSA genotypes.

In the current study we found patients with chronic illness had twofold increase in the risk of acquiring MRSA compared to patients with acute illness. Similar findings have been reported earlier [16, 17]. This can be due to the fact that most of the patients with chronic disease visit hospital often and thus increasing the chance of acquiring the pathogen. Previous studies have reported exposure to antibiotic is associated with risk of MRSA colonization [18, 38]. Our findings showed a trend of but non-significantly higher MRSA among patients with previous exposure to antibiotics. This could be due to our small sample size. Alternatively, there is a possibility that some of the patients may have not recalled properly the information on antibiotic use for the past 3 months and even for those who reported some could not mention the name of antibiotic or type of drug used thus underestimating the role of this factor as risk for MRSA acquisition. Furthermore, our findings differ from the findings of other studies, which have reported history of previous hospitalization to be associated with increased risk of MRSA carriage [18, 38]. The lack of association may be due to the small number of patients with such risk in the population investigated resulting into lack of power to identify such associations, and this is another limitation of our study. Studies conducted elsewhere have strongly suggested that males have a higher risk of MRSA carriage $[39,40]$. In this study, we observed that the risk of acquiring MRSA strain were twice higher in male than in the female patients. This could be attributed 
by gender differences in behavior practices and hygiene such as hand washing and use of soap or playing contact sports and occupation, which may influence MRSA colonization. Other risk factors associated with MRSA colonization have been reported elsewhere $[9,11,41]$ but we found no association with age or level of education.

\section{Conclusion}

We report a high prevalence of MRSA among patients on admission at the two municipal hospitals in Dar es Salaam, Tanzania. The high prevalence of MRSA and the increased rates of resistance to commonly used antimicrobials among MRSA isolates call for attention to the importance of including the screening of MRSA in our hospitals setting in order to prevent further spread of MRSA strains to other patients and to the communities. Control and prevention strategies should be emphasized including decolonization of careers.

\section{Abbreviations \\ CLSI: clinical and laboratory standards institute guidelines; MUHAS: Muhimbili University of Health and Allied Sciences; MPL: microbiology pathology labora- tory; MRSA: methicillin resistant Staphylococcus aureus; MSSA: methicillin- susceptible S. aureus; $M_{L} S_{B}$ : macrolide-lincosamide-streptogramin $B ; C_{B} M L S_{B}$ : constitutive resistance; $\mathrm{iMLS}_{\mathrm{B}}$ : clindamycin inducible resistance.}

\section{Authors' contributions}

AJ, SJM, MM, EM, NM, SA and EFL participated in the study conception and study design. AJ and LN were responsible for data collection and the laboratory testing. AJ and SJM analysed the data. AJ wrote the initial draft of the manuscript, which was reviewed critically by SJM, EFL and MM. All the coauthors participated in revising the manuscript. All authors read and approved the final manuscript.

\section{Author details \\ ${ }^{1}$ Department of Microbiology and Immunology, Muhimbili University of Health and Allied Sciences, Dar Es Salaam, Tanzania. ${ }^{2}$ Department of Clinical Science, University of Bergen, Bergen, Norway. ${ }^{3}$ Department of Epidemiol- ogy and Biostatistics, Muhimbili University of Health and Allied Sciences, Dar Es Salaam, Tanzania. ${ }^{4}$ Department of Surgery, Muhimbili University of Health and Allied Sciences, Dar Es Salaam, Tanzania.}

\section{Acknowledgements}

We are grateful to all the patients who participated in the study. We thank all the laboratory personnel at MUHAS Microbiology laboratory for their technical support. We also thank Zaipha Katabaro and the nurses at the two regional hospitals for their cooperation in sample collection.

\section{Competing interests}

The authors declare that they have no competing interests.

\section{Availability of data}

All relevant data generated and analyzed during this study are included in this manuscript.

\section{Ethical approval and consent to participate}

Ethical clearance was obtained from the Senate Research and Publications Committee of Muhimbili University of Health and Allied Sciences in Dar es Salaam, Tanzania. This study was conducted in accordance with the Declaration of Helsinki. Written informed consent was obtained from each patient and from parents/guardians for participants below the legal age of consent before enrolment. Permission to conduct the study was obtained from hospital authorities where the study was conducted. Consent to publish the findings of this study was also sought from the participants/guardian in manner that will not disclose any direct personal information.

\section{Funding}

This work was supported financially by the Swedish International Development Cooperation Agency (Sida) supported core funds at MUHAS.

\section{Publisher's Note}

Springer Nature remains neutral with regard to jurisdictional claims in published maps and institutional affiliations.

Received: 7 December 2016 Accepted: 21 July 2017

Published online: 22 August 2017

\section{References}

1. Layton MC, Hierholzer WJ, Patterson JE. The evolving epidemiology of methicillin-resistant Staphylococcus aureus at a university hospital. Infect Control Hosp Epidemiol. 1995;16:12-7.

2. Shiv-Sekhar C, Pallab R, Arun A, Anindita D, Meera S. A community-based study on nasal carriage of Staphylococcus aureus. Indian J Med Res. 2009;130:742-8.

3. Williams VR, Callery S, Vearncombe M, Simor AE. The role of colonization pressure in nosocomial transmission of methicillin-resistant Staphylococcus aureus. Am J Infect Control. 2009;37:106-10.

4. Huang SS, Platt R. Risk of methicillin-resistant Staphylococcus aureus infection after previous infection or colonization. Clin Infect Dis, 2003;36:281-5.

5. Corbella X, Domínguez MA, Pujol M, Ayats J, Sendra M, Pallares R, et al. Staphylococcus aureus nasal carriage as a marker for subsequent staphylococcal infections in intensive care unit patients. Eur J Clin Microbiol Infect Dis. 1997;16:351-7.

6. Moreillon P, Que YA, Glauser MP. Staphylococcus aureus (including staphylococcal toxic shock). In: Mandell GL, Bennett JE, Dolin R, editors. Mandell, Douglas and Bennett's principles and practice of infectious diseases. Philadelphia: Elsevier Churchill Livingstone Publishers; 2005. p. 2321-48.

7. Troillet N, Carmeli YE, Samore MH, Dakos J, Eichelberg K, DeGirolami PC, et al. Carriage of methicillin-resistant Staphylococcus aureus at hospital admission. Infect Control Hosp Epidemiol. 1998;19:181-5.

8. Davis KA, Stewart JJ, Crouch HK, Florez CE, Hospenthal DR. Methicillinresistant Staphylococcus aureus (MRSA) nares colonization at hospital admission and its effect on subsequent MRSA infection. Clin Infect Dis. 2004:39:776-82.

9. Santos HB, Machado DP, Camey SA, Kuchenbecker RS, Barth AL, Wagner MB. Prevalence and acquisition of MRSA amongst patients admitted to a tertiary-care hospital in Brazil. BMC Infect Dis. 2010;10:328.

10. Harbarth S, Fankhauser C, Schrenzel J, Christenson J, Gervaz P, BandieraClerc C, et al. Universal screening for methicillin-resistant Staphylococcus aureus at hospital admission and nosocomial infection in surgical patients. JAMA. 2008;299:1149-57.

11. Lucet JC, Grenet K, Armand-Lefevre L, Harnal M, Bouvet E, Regnier B, et al. High prevalence of carriage of methicillin-resistant Staphylococcus aureus at hospital admission in elderly patients: implications for infection control strategies. Infect Control Hosp Epidemiol. 2005:26:121-6.

12. Murthy A, De Angelis G, Pittet D, Schrenzel J, Uckay I, Harbarth S. Costeffectiveness of universal MRSA screening on admission to surgery. Clin Microbiol Infect. 2010;16:1747-53.

13. Kalmeijer MD, van Nieuwland-Bollen E, Bogaers-Hofman D, de Baere GAJ, Kluytmans JAJW. Nasal carriage of Staphylococcus aureus is a major risk factor for surgical-site infections in orthopedic surgery. Infect Control Hosp Epidemiol. 2000;21:319-23.

14. Sai N, Laurent C, Strale H, Denis O, Byl B. Efficacy of the decolonization of methicillin-resistant Staphylococcus aureus carriers in clinical practice. Antimicrob Resist Infect Control. 2015;4:56.

15. Graffunder EM, Venezia RA. Risk factors associated with nosocomial methicillin-resistant Staphylococcus aureus (MRSA) infection including previous use of antimicrobials. J Antimicrob Chemother. 2002:49:999-1005. 
16. Crum-Cianflone NF, Burgi AA, Hale BR. Increasing rates of communityacquired methicillin-resistant Staphylococcus aureus infections among HIV-infected persons. Int J STD AIDS. 2007;18:521-6.

17. Ziakas PD, Anagnostou T, Mylonakis E. The Prevalence and significance of methicillin-resistant Staphylococcus aureus colonization at admission in the general ICU setting: a meta-analysis of published studies. Crit Care Med. 2014:42:433-44.

18. Tacconelli E, De Angelis G, Cataldo MA, Pozzi E, Cauda R. Does antibiotic exposure increase the risk of methicillin-resistant Staphylococcus aureus (MRSA) isolation? A systematic review and meta-analysis. J Antimicrob Chemother. 2008:61:26-38.

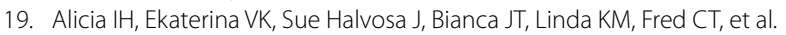
Risk factors for colonization with methicillin-resistant Staphylococcus aureus (MRSA) in patients admitted to an urban hospital: emergence of community-associated MRSA nasal carriage. Clin Infect Dis. 2005;41:159-66

20. Kluytmans J, van Belkum A, Verbrugh H. Nasal carriage of Staphylococcus aureus: epidemiology, underlying mechanisms, and associated risks. Clin Microbiol Rev. 1997;3:505-20.

21. Papia G, Louie M, Tralla A, Johnson C, Collins V, Simor A. Screening highrisk patients for methicillin resistant Staphylococcus aureus on admission to the hospital: is it cost effective? Infect Control Hosp Epidemiol. 1999;20:473-7.

22. Fishbain JT, Lee JC, Nguyen HD, Mikita JA, Mikita CP, Uyehara CF, et al. Nosocomial transmission of methicillin-resistant Staphylococcus aureus: a blinded study to establish baseline acquisition rates. Infect Control Hosp Epidemiol. 2003;24:415-21.

23. Yilmaz G, Aydin K, Iskender S, Caylan R, Koksal I. Detection and prevalence of inducible clindamycin resistance in Staphylococci. J Med Microbiol. 2007:56:342-5.

24. Fiebelkorn KR, Crawford SA, McElmeel ML, Jorgensen JH. Practical disc diffusion method for detection of inducible clindamycin resistance in Staphylococcus aureus and coagulase-negative Staphylococci. J Clin Microbiol. 2003;41:4740-4.

25. Siberry GK, Tekle T, Carroll K, Dick J. Failure of clindamycin treatment of methicillin-resistant Staphylococcus aureus expressing inducible clindamycin resistance in vitro. Clin Infect Dis. 2003;37:1257-60.

26. Sasirekha B, Usha MS, Amruta JA, Ankit S, Brinda N, Divya R. Incidence of constitutive and inducible clindamycin resistance among hospitalassociated Staphylococcus aureus. Biotech. 2014:4:85-9.

27. Urassa WK, Haule EA, Kagoma C, Langeland N. Antimicrobial susceptibility of Staphylococcus aureus strains at Muhimbili medical centres, Tanzania. East Afr Med J. 1999;76:693-5.

28. Blomberg B, Manji KP, Urassa WK, Tamim BS, Mwakagile DSM, Jureen R, et al. Antimicrobial resistance predicts death in Tanzanian children with bloodstream infections: a prospective cohort study. BMC Infect Dis. 2007;7:43.
29. Mshana SE, Kamugisha E, Mirambo M, Chalya P, Rambau P, Mahalu W, et al. Prevalence of clindamycin inducible resistance among methicillinresistant Staphylococcus. Tanzan J Health Res. 2009;11:59-64.

30. Moyo S, Aboud S, Kasubi M, Maselle SY. Bacteria isolated from bloodstream infections at a tertiary hospital in Dar es Salaam, Tanzania antimicrobial resistance of isolates. S Afr Med J. 2012;100:835-8.

31. CLSI. Performance standards for antimicrobial susceptibility testing; twenty fifth informational supplement CLSI document M100-S25: Wayne, PA: clinical and laboratory standards institute; 2015.

32. Scriven JM, Silva P, Swann RA, Thompson MM, Naylor AR, Bell PRF, et al. The acquisition of methicillin-resistant Staphylococcus aureus (MRSA) in vascular patients. Eur J Vasc Endovasc Surg. 2003;25:147-51.

33. Hogue JS, Buttke P, Braun LE, Fairchok MP. Mupirocin resistance related to increasing mupirocinuse in clinical isolates of methicillin-resistant Staphylococcus aureus in a pediatric population. J Clin Microbial. 2010:48:2599-600.

34. McNeil JC, Hulten KG, Kaplan SL, Mason EO. Mupirocin resistance in Staphylococcus aureus causing recurrent skin and soft tissue infections in children. Antimicrob Agents Chemother. 2011;55:2431-3.

35. Upton A, Lang S, Heffernan H. Mupirocin and Staphylococcus aureus: recent paradigm of emerging antibiotic resistance. J Antimicrob Chemother. 2003:51:613-7.

36. Orrett FA. The emergence of mupirocin resistance among clinical isolates of methicillin-resistant Staphylococcus aureus in Trinidad: a first report. Jpn J Infect Dis. 2008;61:107-10

37. Vivoni AM, Santos KR, de-Oliveira MP, Giambiagi-deMarval M, Ferreira AL, Riley LW, et al. Mupirocin for controlling methicillin-resistant Staphylococcus aureus: lessons from a decade of use at a university hospital. Infect Control Hosp Epidemiol. 2005;26:662-7.

38. Baraboutis IG, Tsagalou EP, Papakonstantinou I, Marangos MN, Gogos C, Skoutelis AT, et al. Length of exposure to the hospital environment is more important than antibiotic exposure in healthcare associated infections by methicillin-resistant Staphylococcus aureus: a comparative study. Braz J Infect Dis. 2011;15:426-35

39. Harbarth S, Sax H, Fankhauser-Rodriguez C, Schrenzel J, Agostinho A, Pitter D. Evaluating the probability of previously unknown carriage of MRSA at hospital admission. Am J Med. 2006;119(275):e15-23.

40. Humphreys H, Fitzpatick F, Harvey BJ. Gender differences in rates of carriage and bloodstream infection caused by methicillin-resistant Staphylococcus aureus: are they real, do they matter and why? Clin Infect Dis. 2015;61:1708-14

41. Seybold U, Supthut-Schroder B, Draenert R, Hogardt M, Bogner JR. Prevalence and risk factors of nasal colonization with Staphylococcus aureus-association with HIV infection in older patients. Scand J Infect Dis. 2009:41:63-6.

\section{Submit your next manuscript to BioMed Central and we will help you at every step:}

- We accept pre-submission inquiries

- Our selector tool helps you to find the most relevant journal

- We provide round the clock customer support

- Convenient online submission

- Thorough peer review

- Inclusion in PubMed and all major indexing services

- Maximum visibility for your research

Submit your manuscript at www.biomedcentral.com/submit
BioMed Central 